University of Wollongong

Research Online

Faculty of Engineering and Information

Faculty of Engineering and Information

Sciences - Papers: Part A

Sciences

$1-1-2013$

Dynamic of negative ions in potassium-D-ribose collisions

D Almeida

Universidade Nova De Lisboa

F Ferreira da Silva

Universidade Nova De Lisboa

G Garcia

University of Wollongong

P Limao-Vieira

Universidade Nova De Lisboa

Follow this and additional works at: https://ro.uow.edu.au/eispapers

Part of the Engineering Commons, and the Science and Technology Studies Commons

Research Online is the open access institutional repository for the University of Wollongong. For further information contact the UOW Library: research-pubs@uow.edu.au 


\title{
Dynamic of negative ions in potassium-D-ribose collisions
}

\begin{abstract}
We present negative ion formation from collisions of neutral potassium atoms with D-ribose (C5H1005), the sugar unit in the DNA/RNA molecule. From the negative ion time-of-flight (TOF) mass spectra, $\mathrm{OH}-$ is the main fragment detected in the collision range $50-100 \mathrm{eV}$ accounting on average for $50 \%$ of the total anion yield. Prominence is also given to the rich fragmentation pattern observed with special attention to $0-(16 \mathrm{~m} / \mathrm{z})$ formation. These results are in sharp contrast to dissociative electron attachment experiments. The TOF mass spectra assignments show that these channels are also observed, albeit with a much lower relative intensity. Branching ratios of the most abundant fragment anions as a function of the collision energy are obtained, allowing to establish a rationale on the collision dynamics.
\end{abstract}

\section{Keywords}

dynamic, ions, collisions, negative, potassium, ribose

Disciplines

Engineering | Science and Technology Studies

\section{Publication Details}

Almeida, D., da Silva, F. Ferreira., Garcia, G. \& Limao-Vieira, P. (2013). Dynamic of negative ions in potassium-D-ribose collisions. Journal of Chemical Physics, 139 (11), 114304-1-114304-6. 


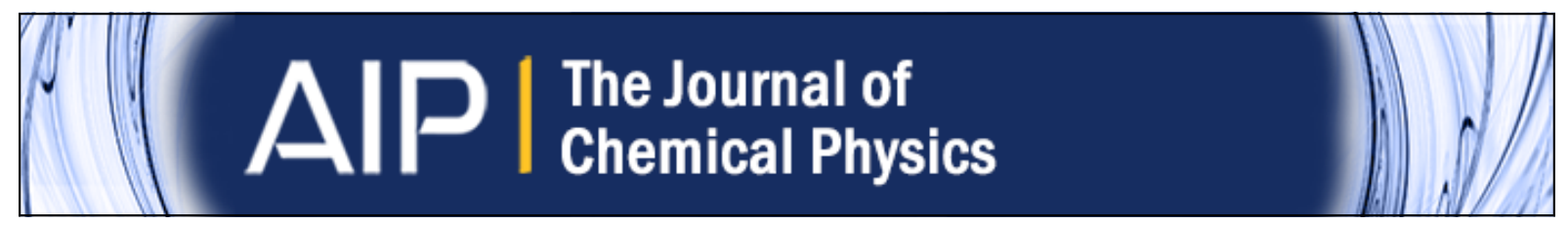

Dynamic of negative ions in potassium-D-ribose collisions

D. Almeida, F. Ferreira da Silva, G. García, and P. Limão-Vieira

Citation: The Journal of Chemical Physics 139, 114304 (2013); doi: 10.1063/1.4820949

View online: http://dx.doi.org/10.1063/1.4820949

View Table of Contents: http://scitation.aip.org/content/aip/journal/jcp/139/11 ?ver=pdfcov

Published by the AIP Publishing

Advertisement:

AlP Re-register for Table of Content Alerts

Create a profile.

Sign up today! 


\title{
Dynamic of negative ions in potassium-D-ribose collisions
}

\author{
D. Almeida, ${ }^{1}$ F. Ferreira da Silva, ${ }^{1}$ G. García, ${ }^{2,3}$ and P. Limão-Vieira ${ }^{1,4, a)}$ \\ ${ }^{1}$ Laboratório de Colisóes Atómicas e Moleculares, CEFITEC, Departamento de Física, Faculdade de Ciências \\ e Tecnologia, Universidade Nova de Lisboa, 2829-516 Caparica, Portugal \\ ${ }^{2}$ Instituto de Física Fundamental, Consejo Superior de Investigaciones Científicas, Serrano 113-bis, \\ 28006 Madrid, Spain \\ ${ }^{3}$ Centre for Medical Radiation Physics, University of Wollongong, NSW 2522, Australia \\ ${ }^{4}$ Centre for Earth, Planetary, Space and Astronomical Research, Department of Physical Sciences, \\ The Open University, Walton Hall MK7 6AA, United Kingdom
}

(Received 7 June 2013; accepted 25 August 2013; published online 17 September 2013)

\begin{abstract}
We present negative ion formation from collisions of neutral potassium atoms with D-ribose $\left(\mathrm{C}_{5} \mathrm{H}_{10} \mathrm{O}_{5}\right)$, the sugar unit in the DNA/RNA molecule. From the negative ion time-of-flight (TOF) mass spectra, $\mathrm{OH}^{-}$is the main fragment detected in the collision range 50-100 eV accounting on average for $50 \%$ of the total anion yield. Prominence is also given to the rich fragmentation pattern observed with special attention to $\mathrm{O}^{-}(16 \mathrm{~m} / \mathrm{z})$ formation. These results are in sharp contrast to dissociative electron attachment experiments. The TOF mass spectra assignments show that these channels are also observed, albeit with a much lower relative intensity. Branching ratios of the most abundant fragment anions as a function of the collision energy are obtained, allowing to establish a rationale on the collision dynamics. @ 2013 AIP Publishing LLC. [http://dx.doi.org/10.1063/1.4820949]
\end{abstract}

\section{INTRODUCTION}

Further to the recent studies on the damaging capability of low energy electrons (LEEs) to decompose DNA, ${ }^{1}$ studying electron interactions with its constituents provides valuable insight into the fundamental mechanisms underlying such damage. A recent study has shown that electrondriven reactions to DNA, yielding single, double, and clustered lesions, can be explained through damage to its building blocks, i.e., the nucleobases, the sugar unit, and the phosphate groups. ${ }^{1,2}$ In the light of these ground-breaking studies, an increased attention to low energy electron interactions with DNA/RNA subunits has been observed. As such, studying chemical reactions for biomolecular systems is relevant to understand radiation induced damage at the molecular level. Recent developments of Monte Carlo-based empirical simulations on pseudo-physiological environment allow us to model electron (and positron) tracks that result from the interaction of high energy quanta through a given tissue-equivalent material (TEM) ${ }^{3-7}$ At the moment, however, the simulations are restricted to rather simplistic TEMs, ${ }^{6-8}$ owing to the empirical nature of these models requiring information on the cross sections and dynamics of the underlying physicochemical processes. Therefore, the study of fundamental molecular mechanisms is of particular relevance to allow for these models to encompass increasingly (and therefore more accurate) descriptions of the physiological environment's response to radiation-induced changes. In the particular case of the DNA/RNA sugar unit or a given substitute, knowledge on electron elastic and inelastic scattering is quite well established (see, e.g., Ref. 9), which is also the case of disso-

\footnotetext{
a) Author to whom correspondence should be addressed. Electronic mail: plimaovieira@fct.unl.pt. Tel.: (+351) 2129478 59. Fax: (+351) 21294 8549.
}

ciative electron attachment (DEA) processes. ${ }^{1,10-17}$ However, data on the interaction with electron-donating projectiles, i.e., electron transfer processes in potassium-molecule collisions, are, as far as authors are aware, absent. As such, studying the processes that occur in the context of electron transfer in atom-molecule collisions can be a stepping stone in our understanding of some of the molecular mechanisms that can happen in non-gas-phase environments. In particular, studying the role of the sugar unit is critical, as it is now well established that one of the main sources of possible damage to DNA/RNA stems from changes in the D-ribose (DR) unit. ${ }^{18}$

Recently, we have pursued in our laboratory a series of detailed studies on negative ion formation in collisions of potassium atoms with several bio-related molecular targets. ${ }^{19-25}$ Further to the studies of atomic collisions with nucleobases, ${ }^{23}$ herein we present the negative ion fragmentation pattern from collisions of potassium atoms with the D-ribose molecule $\left(\mathrm{C}_{5} \mathrm{H}_{10} \mathrm{O}_{5}\right)$, the monosaccharide pentose ring in the DNA/RNA structure. The mechanism studied in these collisions is the transfer of the unpaired valence electron of a neutral hyperthermal potassium atom $(\mathrm{K})$ to a target molecule $(\mathrm{AB})$. The electron transfer mechanism is only possible at particular potassium-molecule distances, the crossing radius, $R_{\mathrm{c}}$, with a rough estimate of $\sim 3.2 \AA$ for the present case. Briefly, in atom-molecule collisions, where an adiabatic electron transfer occurs, a negative ion is formed as part of an intermediate step or as a final product. The electron transfer process happens when electrons follow adiabatically the nuclear motion in the vicinity of the crossing of the stationary non-perturbed states, i.e., the covalent and the ionic diabatic states (from the crossing of the covalent and the ionic diabatic potential surfaces) at large atom-molecule distances. The ionic surface lies above the covalent surface, the endoergicity being $\Delta \mathrm{E}=\mathrm{IE}(\mathrm{K})-\mathrm{EA}(\mathrm{AB})$, where IE stands 
for the ionisation energy of the potassium atom and EA the electron affinity of the target molecule. However, due to the coulombic interaction, there is a crossing seam for which both stationary non-adiabatic potential energy surfaces have the same value. During the collision process and near that crossing, there can be a perturbation of the stationary states induced by the projectile/target nuclear motion leading to a coupling. This leads after the collision path to the formation of a positive ion $\mathrm{K}^{+}$and a molecular anion, which may even allow access to parent molecular states that are otherwise not accessible in free electron attachment experiments. ${ }^{22,23,26}$ In particular, states with a positive electron affinity can be formed, and the role of vibrational excitation of the parent neutral molecule can be studied ${ }^{27}$ by the collision dynamics. ${ }^{19}$

Another consequence of the $\mathrm{K}^{+}$presence is that even if the free negative molecular ion is unstable with respect to autodetachment, in the collision complex it can be stabilized at distances shorter than the crossing between the two potential energy surfaces. This is due to the attractive interaction with the positive ion, $\mathrm{K}^{+} .{ }^{26}$ Indeed, recent measurements of anion collisions $\left(\mathrm{H}^{-}, \mathrm{O}^{-}\right.$, and $\left.\mathrm{OH}^{-}\right)$with nitromethane $\left(\mathrm{CH}_{3} \mathrm{NO}_{2}\right)$ indicate that the autodetachment suppression mechanism is not as efficient as in neutral atommolecule collisions, ${ }^{28}$ which can be rationalized as the interaction between the resulting molecular anion and neutral projectile being much weaker than the coulombic interaction that persists in neutral atom-molecule collisions.

As far as DEA is concerned, several studies have been already performed on the DR molecule ${ }^{1,10,11,13}$ and its substitutes, ${ }^{15}$ particularly using isotopic labelling, which showed a remarkable site selectivity in the fragmentation channels yielding $\left(\mathrm{DR}-\mathrm{H}_{2} \mathrm{O}\right)^{-}$formation. ${ }^{10}$ The water abstraction sites were explored in more detail in this study, and a tentative identification of some sequential reaction channels was performed. ${ }^{10}$

Another interesting study using a Fourier transform ion cyclotron resonance mass spectrometer and density functional theory (DFT) calculations ${ }^{29}$ concluded that, upon heating in the gas-phase D-ribose, the molecule changes its geometry to form a pyranose structure (six-membered ring) rather than keeping its furanose form (five-membered ring), the latter present in the DNA/RNA framework. ${ }^{29}$ As such, this study concludes that the dominant conformer in gas-phase D-ribose is the pyranose form.

In this work, we focus our attention on the negative ion formation in collisions of neutral potassium atoms (50 $-100 \mathrm{eV}$ lab frame) with D-ribose molecules. In Sec. II, we provide a brief summary of the experimental setup. In Sec. III, we present and discuss the negative ion mass spectra. Where and when possible, comparisons with available DEA data will provide relevant information of the electronic structure of the target molecule. Finally, in Sec. IV, some conclusions will be drawn regarding the importance of these studies as far as state of the art electron-driven DNA/RNA damage is concerned.

\section{EXPERIMENTAL DETAILS}

The experimental setup used to obtain the negative ion time-of-flight (TOF) mass spectra has been described elsewhere. ${ }^{23,26}$ Briefly, an effusive molecular beam crosses a primary beam of fast neutral potassium $(\mathrm{K})$ atoms. $\mathrm{K}^{+}$ions produced in a potassium ion source were accelerated to 50 $-100 \mathrm{eV}$, before passing through an oven where they resonantly charge exchange with neutral potassium to produce a beam of fast (hyperthermal) atoms. Residual ions from the primary beam are removed by electrostatic deflecting plates outside the oven. The intensity of the neutral potassium beam was monitored using a Langmuir-Taylor ionisation detector, before and after the TOF mass spectra collection. The effusive beam of DR was then introduced into a $1 \mathrm{~mm}$ diameter source where it was crossed with the neutral hyperthermal potassium beam between two parallel plates at $1.2 \mathrm{~cm}$ mutual separation. The anions produced were extracted by a $220 \mathrm{~V} \mathrm{~cm}^{-1}$ pulsed electrostatic field. The typical base pressure in the collision chamber was $8 \times 10^{-5} \mathrm{~Pa}$ and the working pressure upon heating the powder samples was $2 \times 10^{-4}$ $\mathrm{Pa}$. Mass spectra were obtained by subtracting the background signal from the sample measurements. TOF mass spectra calibration was carried out on the basis of the well-known anionic species formed after potassium collisions with the nitromethane molecule. ${ }^{23,26}$ This allows for safe mass assignment, even when the width of the peaks is larger than $1 \mathrm{~m} / \mathrm{z}$.

The solid sample used in the present experiment was purchased from Sigma-Aldrich with a minimum purity of $\geq 99 \%$. It was used as delivered. The sample was heated up to $373 \mathrm{~K}$. In order to test for any thermal decomposition, the spectra were recorded at different temperatures (up to $\sim 400 \mathrm{~K}$ ). No differences were observed in the relative peak intensities as a function of the heating temperature. The extraction region and the TOF system were heated throughout measurements in order to prevent any sample condensation and thence charge accumulation on the electrodes. It is worth noting that the width of the mass peaks may give information on the kinetic energy release distribution of the fragment. However, such approach would require a substantially different treatment of the experimental data, which is not within the scope of the present study.

\section{RESULTS AND DISCUSSION}

The negative ion TOF mass spectra obtained for 50,75 , and $100 \mathrm{eV}$ potassium collision energies in the lab frame are presented in Figs. 1(a)-1(c), and peak assignments in Table I. Additionally, branching ratios for the major fragments as a function of the collision energy are shown in Fig. 2. A brief analysis of these data shows that the most abundant fragments are assigned to $\mathrm{OH}^{-}(17 \mathrm{~m} / \mathrm{z})$, followed by $\mathrm{O}^{-}(16 \mathrm{~m} / \mathrm{z})$ and $\mathrm{C}_{3} \mathrm{H}_{6} \mathrm{OH}^{-} / \mathrm{CH}_{3} \mathrm{COO}^{-}(59 \mathrm{~m} / \mathrm{z})$. One can clearly see that there is evidence of neither the parent nor its dehydrogenated anion formation, where the latter was only reported in previous DEA studies. ${ }^{10,11,13,15}$ A close inspection of Table I reveals that fragment anions $\mathrm{m} / \mathrm{z} 25,41,43$, and 45 were not reported in DEA experiments. Regarding the absence of the dehydrogenated parent anion (DR-H) ${ }^{-}$formation, it is interesting to note that in DEA its resonance profile (shape and energy position) is similar to other fragments. ${ }^{13}$ This implies that, while the initial accessed state may be the same, it then opens up different fragmentation pathways. In 


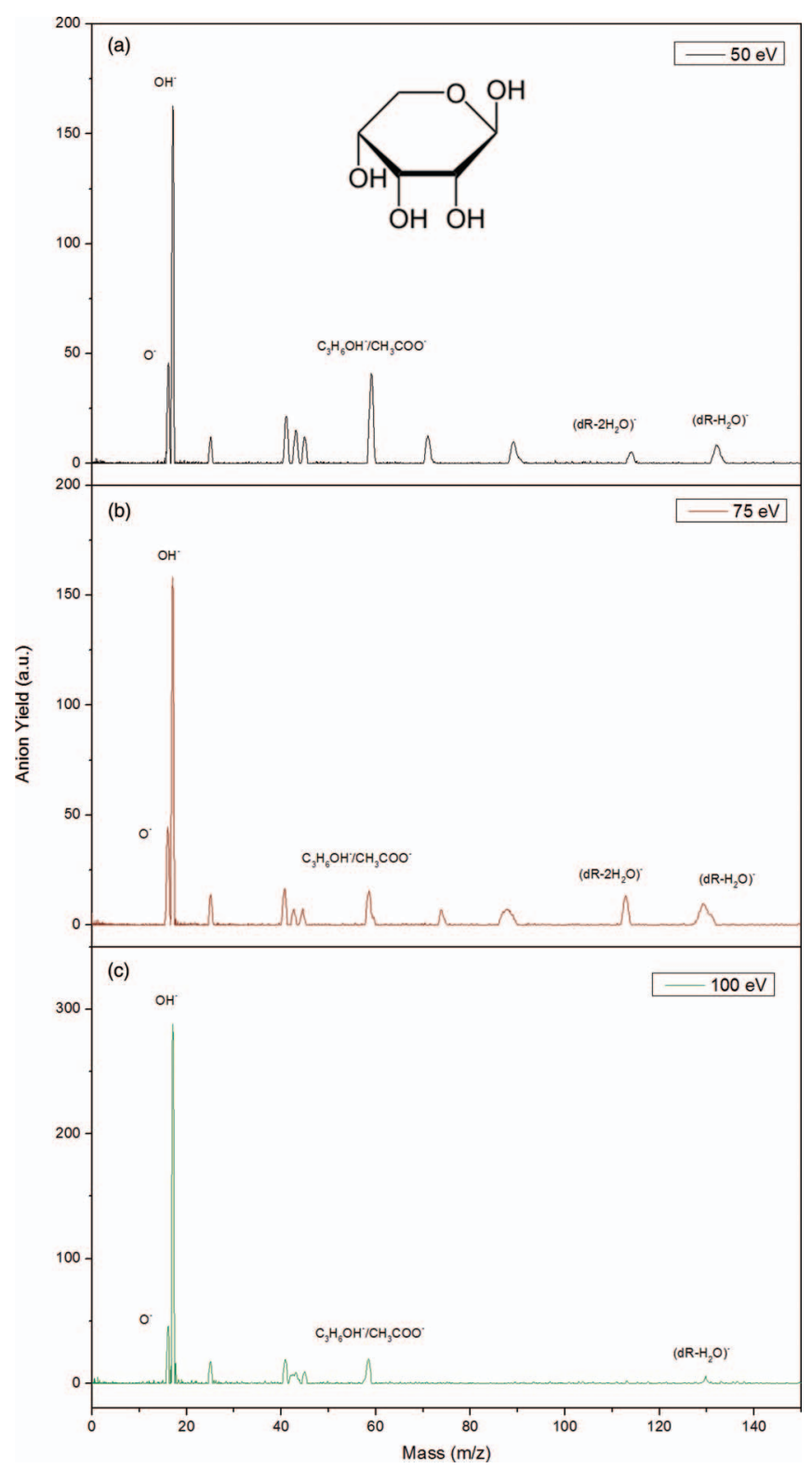

FIG. 1. Negative TOF mass spectra in potassium-D-ribose collisions at (a) $50 \mathrm{eV}$, (b) $75 \mathrm{eV}$, and (c) $100 \mathrm{eV}$ collision energy in the lab frame. An inset with the dominant conformer is added. ${ }^{29}$

this context, it is plausible to reason that the pathway resulting in (DR-H) ${ }^{-}$formation will not be able to compete with the other fragmentation pathways. Since the main difference between DEA and electron transfer lies on the presence of the potassium cation post-collision, it stands to reason that the potassium cation may indeed be the cause for this discrepancy. Another possible rationale for such absent channel may reside on the fact that upon electron capture the sugar ring may pucker, which will lead to an increased chance of overlapping between molecular orbitals. This in turn may enhance intramolecular electron transfer between $\pi^{*}$ and $\sigma^{*}$ orbitals. This then leads to an inability of the electron to stay in a less anti-bonding orbital, which in turn may result in prompt dissociation.

As mentioned before, the dominant conformer in gasphase D-ribose is the six-membered pyranose form ring,
TABLE I. Assignment of TOF mass spectrum anions in collisions of potassium atoms with D-ribose. Comparisons are made with the available DEA studies to deoxyribose and fructose molecules. M means parent.

\begin{tabular}{|c|c|c|c|}
\hline \multirow[b]{2}{*}{ Proposed anion assignment } & \multirow[b]{2}{*}{ This work } & \multicolumn{2}{|c|}{ DEA studies } \\
\hline & & Deoxyribose $^{10,11,13}$ & Fructose $^{15}$ \\
\hline $\mathrm{H}^{-}$ & $x$ & $x$ & $\checkmark$ \\
\hline $\mathrm{O}^{-}$ & $\checkmark$ & $\checkmark$ & $\checkmark$ \\
\hline $\mathrm{OH}^{-}$ & $\checkmark$ & $\checkmark$ & $\checkmark$ \\
\hline $\mathrm{C}_{2} \mathrm{H}^{-}$ & $\checkmark$ & $x$ & $x$ \\
\hline $\mathrm{C}_{2} \mathrm{HO}^{-}$ & $\checkmark$ & $x$ & $x$ \\
\hline $\mathrm{C}_{2} \mathrm{H}_{3} \mathrm{O}^{-}$ & $\checkmark$ & $x$ & $x$ \\
\hline $\mathrm{HCOO}^{-}$ & $\checkmark$ & $x$ & $\checkmark$ \\
\hline $\mathrm{C}_{3} \mathrm{H}_{6} \mathrm{OH}^{-} / \mathrm{CH}_{3} \mathrm{COO}^{-}$ & $\checkmark$ & $\checkmark$ & $x$ \\
\hline $\mathrm{C}_{3} \mathrm{H}_{4} \mathrm{O}_{2}^{-}$ & $\checkmark$ & $\checkmark$ & $\checkmark$ \\
\hline $\mathrm{C}_{3} \mathrm{H}_{5} \mathrm{O}_{3}^{-}$ & $\checkmark$ & $\checkmark$ & $x$ \\
\hline$\left(\mathrm{M}-2 \mathrm{H}_{2} \mathrm{O}\right)$ & $\checkmark$ & $\checkmark$ & $\checkmark$ \\
\hline$\left(\mathrm{M}-\mathrm{H}_{2} \mathrm{O}\right)$ & $\checkmark$ & $\checkmark$ & $\checkmark$ \\
\hline$(\mathrm{M}-\mathrm{H})$ & $x$ & $\checkmark$ & $x$ \\
\hline
\end{tabular}

which is structurally analogous to fructose. Additionally it is worth noting that a theoretical study has determined that the dipole moment for such conformers lies between 3 and $4 \mathrm{D}$, which has been shown to be enough to support dipolebound anion states. We now discuss the majority of the anions formed in such potassium-molecule collisions.

\section{A. $\left(\text { DR- } \mathrm{H}_{2} \mathrm{O}\right)^{-}$and (DR-2 $\left.\mathrm{H}_{2} \mathrm{O}\right)^{-}$}

The fragment anion m/z 132 can be assigned to the loss of one hydroxyl and hydrogen group, whereas m/z 114 to the abstraction of two hydroxyl and hydrogen radicals. An ensuing discussion of certain aspects of these fragmentation channels leads to the following questions: (1) do hydrogen and hydroxyl excision lead to a water molecule formation? (2) from which positions do the fragments stem from? and (3) given that some of the neutral fragments do not require ring breaking, does the molecular anion remain in its ring form? Regarding the first, such fragment anions have been also reported in DEA studies. ${ }^{10,11,13,15}$ In the case of fructose, it was

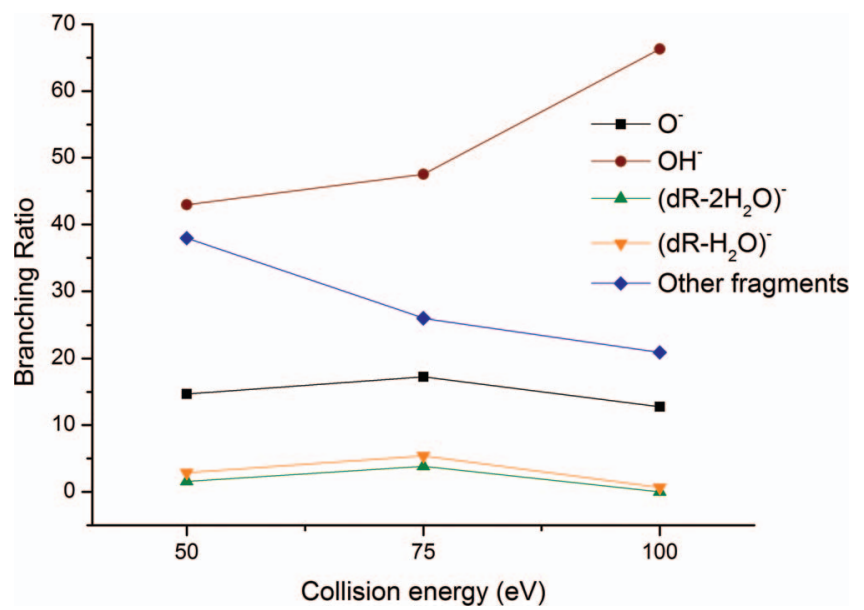

FIG. 2. Branching ratios for the anions as a function of the collision energy. Error bars are within the data points and so not visible. 
shown that formation of a water molecule is exothermic by $-242 \mathrm{~kJ} \mathrm{~mol}^{-1}(-2.51 \mathrm{eV})$. Furthermore, positive ion spectra in electron interactions with D-ribose report the presence of $\mathrm{H}_{2} \mathrm{O}^{+}{ }^{13,15}$ This therefore leads to the conclusion that the abstraction of the hydrogen and hydroxyl radicals will result in the formation of one (or two) water molecule(s).

The second question pertains to site selectivity in the formation of these fragments. Indeed, as was shown in DEA studies that make a criterion use of isotope-labelled ribose rings, formation of water molecules does not appear to stem from the $\mathrm{C}_{1}-\mathrm{H}$ bond. ${ }^{10}$

Regarding the third question, it is known that (DR$\left.\mathrm{H}_{2} \mathrm{O}\right)^{-}$and (DR-2 $\left.\mathrm{H}_{2} \mathrm{O}\right)^{-}$formations stem from accessing the same initial state. According to DEA experiments, ${ }^{13}$ these fragments show near $0 \mathrm{eV}$ resonances reminiscent of dissociation mechanisms present in other molecules, such as the well-explored case of uracil/thymine. ${ }^{30-32}$ Some studies have indeed shown that dissociation through near $0 \mathrm{eV}$ resonances pertains to a molecular mechanism in which an incident electron is captured into a diffuse dipole-bound state (DBS), followed by an intramolecular electron transfer to a valence state that subsequently leads to fragmentation. ${ }^{30-32}$ This "doorway" mechanism is indeed somewhat pervasive, namely, appearing in molecules such as nitromethane ${ }^{33}$ and uracil/thymine. ${ }^{30}$ Indeed, a theoretical study on fructose ${ }^{14}$ shows that it is possible for the pyranose conformer of Dribose to undergo such mechanism. As such, the discussion is centred on the basis of an initial capture of the incoming electron into a dipole-bound state, due to the molecule's considerable average dipole moment $\left(3.2 \mathrm{D}^{14}\right.$ depending on the conformer). Such value is more than enough to warrant the presence of a stable DBS. Subsequently, a transfer of the extra electron to one of the valence states may be possible, but only through an opening of the ring, which in turn will result in fragmentation. This therefore leads to the abstraction of an $\mathrm{H}$ and $\mathrm{OH}$, with the molecular anion becoming acyclical, i.e., losing its ring structure. This study therefore lends support to the conclusion that capture of virtually no-energy electrons will result in formation of an acyclic form of the molecular anion. ${ }^{14}$ As such, in the case of the present study, it can be assumed that the resonance enhanced mechanisms governing such fragmentation channels are the same as in DEA.

A detailed analysis of Fig. 2 shows that, with the exception of $\mathrm{OH}^{-}$and other fragments, $\mathrm{O}^{-},\left(\mathrm{DR}-\mathrm{H}_{2} \mathrm{O}\right)^{-}$, and (DR$\left.2 \mathrm{H}_{2} \mathrm{O}\right)^{-}$branching ratios do not change appreciably with the collision energy, and so do not depend on the collision time. This means that the channels yielding these fragments are not affected by the type of atomic scattering process, i.e., either covalent or ionic (a more concise discussion on the relevance of these scattering processes can be found in Refs. 20 and 34). As such, for those fragments, their branching ratios show the same trend, which is indicative that both dissociative channels are a result of similar collision dynamics.

Finally, owing to the width of the mass peak, it is not possible to unambiguously discard the possibility of sole formation of $\mathrm{OH}$ radicals (either in detriment or in conjunction with), for both m/z 114 and 132 peaks. However, several mass calibrations point towards the aforementioned assignments. Additionally, it is important to note that, given the symmetry between the flanks of the peak, formation of $\mathrm{OH}$ radicals is, at best, negligible at 50 and $100 \mathrm{eV}$ collision energy. In other words, formation of the $\mathrm{OH}$ radical would entail, at least, a difference in the right flank of the TOF mass peak, which may be the case at $75 \mathrm{eV}$ (Fig. 1(b)). However, due to the present mass resolution limitation, no further discussion will be added on this issue.

\section{B. $\mathrm{OH}^{-}$}

$\mathrm{OH}^{-}$is the most abundant fragment ion for all collision energies, amounting for $43 \%$ at $50 \mathrm{eV}$ of the total anion yield and increasing up to $66 \%$ at $100 \mathrm{eV}$ collision energy. Moreover, by gleaning at Fig. 2, $\mathrm{OH}^{-}$relative yield further increases with increasing collision energy. This fact is in sharp contrast with the branching ratios for the other fragments, where for energies higher than $75 \mathrm{eV}$, their relative yields decrease. With such high yield $(>60 \%)$, the dissociation mechanism is indicative of a diatomic-like behaviour along the $\mathrm{C}-$ $\mathrm{OH}$ coordinate(s), which is particularly interesting since such is prevalent in halogenated species such as $\mathrm{C}_{6} \mathrm{H}_{5} \mathrm{~F}{ }^{19}$

In the present study the dominance of this fragmentation channel is in sharp contrast with DEA experiments, in which while present, but at much lower yield than the dominant water-abstraction channels. ${ }^{13,15}$ Such discrepancies between DEA and electron transfer experiments have already been detected in other molecules, most notably regarding the $\mathrm{NCO}^{-}$yield in uracil and thymine. ${ }^{23}$ Briefly, it was shown that, owing to the presence of the potassium cation in the vicinity of the molecular anion, a delay in the autodetachment process of the extra electron occurs, allowing $\pi^{*}$ orbitals to be populated long enough for the electron to be transferred to a highly dissociative $\sigma^{*}$ orbital, ${ }^{23,35}$ which will subsequently lead to fragmentation. Indeed, a recent DEA study to D-ribose shows a resonance profile for $\mathrm{OH}^{-}$formation consisting of one dominant peak at near-zero energy and a weak wider structure at around $7 \mathrm{eV}$, the latter assigned to a shape resonance. ${ }^{11}$ The $\mathrm{OH}^{-}$signal appears as not the main dominant signal in DEA experiments, in contrast with the present experiments. Additionally, the DEA study presents quantum chemical calculations that provide an assignment of a $\pi^{*}$ anionic state to a shape resonance with a lifetime of $\sim 3.1 \mathrm{fs} .{ }^{11}$ This, therefore, can lead one to propose a $\mathrm{OH}^{-}$formation mechanism similar to that responsible for $\mathrm{NCO}^{-}$as in uracil and thymine, ${ }^{23}$ i.e., the potassium cation will, in effect, increase the lifetime of the anionic state formed at $7 \mathrm{eV}$, therefore allowing for fragmentation to successfully compete with autodetachment, thereby leading to an enhancement of the $\mathrm{OH}^{-}$yield. Considering that in electron transfer, autodetachment suppression is much more efficient in the case of ionic scattering, the collision dynamics for $\mathrm{OH}^{-}$formation may be reasonably described by the major contribution of this type of scattering. It is critical to note that higher collision energies imply a smaller probability of ionic scattering. ${ }^{20,34}$ Nevertheless, such assumption seems to be inconsistent with the significant rise of $\mathrm{OH}^{-}$branching ratio, where for higher collision energies a covalent scattering should prevail. However, it is important to stress that the branching ratio does not 
provide information about the absolute rate of formation, but limited to information about the relative yield. As such, one can rationalize by stating that, while a gradual increase of covalent scattering does indeed happen, and therefore a decrease in the probability of $\mathrm{OH}^{-}$formation occurs, it does not necessarily mean that the branching ratio for this fragment decreases. This is even true because such behaviour may be expected for the other fragment anions, and the branching ratio is always obtained by the summation of the total anion yield. Assuming the mechanism proposed above, an interesting discussion that can follow would be to determine if site and bond selectivity mechanisms yielding $\mathrm{OH}^{-}$formation play an important role in the dissociation process. Such selectivity has already been shown in other molecules, both in $\mathrm{DEA}^{36,37}$ and in atom-molecule collision experiments. ${ }^{24,25}$ However, for D-ribose there is no data to sustain such mechanism and due to the fact that $\mathrm{OH}^{-}$appears to stem from only one anionic state (as discussed before), site selectivity in the electron transfer process most likely does not play a relevant role.

\section{C. $\mathrm{O}^{-}$}

$\mathrm{O}^{-}(16 \mathrm{~m} / \mathrm{z})$ presents itself as one of the most intense fragments in the TOF mass spectra, which contrasts with DEA experiments where its yield is only marginal. The $\mathrm{O}^{-}$branching ratio shows a small increase from $15 \%$ (at $50 \mathrm{eV}$ ) to $17 \%$ (at $75 \mathrm{eV}$ ), followed by a small decrease to $13 \%$ (at $100 \mathrm{eV}$ ) (Fig. 2). Further to the discussion above on $\mathrm{OH}^{-}$formation, and given that the energy resonance profile of $\mathrm{O}^{-}$in DEA shows only high energy resonances $(>6 \mathrm{eV})$, it is plausible to attribute $\mathrm{O}^{-}$to a competition with $\mathrm{OH}^{-}$formation through those high-lying resonances. However, in order to further discard $\mathrm{O}^{-}$formation from ring breaking, studies are needed, and at present we are performing electron transfer studies to tetrahydrofuran (THF) in order to specifically address this issue.

\section{Other fragments}

From Figs. 1(a)-1(c), apart from the major anions, the fragmentation pattern is quite rich in other anionic species. In Table I, assignments of the several fragment anions are proposed, where not only the results from DEA experiments to D-ribose studies are considered, ${ }^{10,11,13}$ but, and perhaps more interestingly, results from DEA studies to sugar substitutes ${ }^{15}$ are also reported for comparison. The similarity between the fragmentation patterns in DEA and electron transfer experiments is quite significant, with the main differences lying on the relative yields. From the comparison between D-ribose electron transfer and DEA data on fructose ${ }^{15}$ (one of the sugar substitutes), we also note a similarity between some of the fragmentation patterns, mainly the water abstraction channels, $72\left(\mathrm{C}_{3} \mathrm{H}_{4} \mathrm{O}_{2}{ }^{-}\right), 45\left(\mathrm{HCOO}^{-}\right)$, and $16\left(\mathrm{O}^{-}\right) \mathrm{m} / \mathrm{z}$. Fructose is most likely to be the closest substitute to gas-phase D-ribose, owing to the pyranose form in the gas-phase upon heating the sample. ${ }^{29} \mathrm{~A}$ more thorough study on sugar substitutes in the context of neutral atom collisions would be of great interest, and we are currently pursuing such investigations in our laboratory. Finally, of particular relevance, we note $\mathrm{C}_{2} \mathrm{H}^{-}$formation in the present experiments, which was not reported in DEA studies to deoxyribose and fructose (see Table I). The $\mathrm{C}_{2} \mathrm{H}^{-}$formation requires multiple bond breaking in the precursor anion. However, $\mathrm{C}_{2} \mathrm{H}$ has a considerable high electron affinity $(2.969 \mathrm{eV}),{ }^{38}$ which can explain being observed at all collision energies.

\section{CONCLUSIONS}

The present work provides the first study on negative ion formation in collisions of potassium atoms with D-ribose, the DNA/RNA sugar unit. The fragmentation pattern is similar to recent DEA studies. However, the relative yields of several fragments are significantly different when compared to DEA, in particular for $\mathrm{OH}^{-}$, which is here the dominant ion detected in the TOF mass spectra. The enhancement in the formation of this fragment is proposed to be due to the ability of potassium cation to suppress and/or even delay efficiently autodetachment, an effect that has been increasingly observed as pervasive in the context of atom-molecule collision studies. ${ }^{21-23,28}$ Noteworthy is the fact that neither the parent nor its dehydrogenated negative ions are reported. Finding out if water abstraction channels result indeed in the formation of a water molecule, rather than an abstraction of $\mathrm{H}$ and $\mathrm{OH}$ radicals, remains critical. Due to their quite high reactivity, the efficiency of these radicals as a damaging agent on the surrounding molecules in the biological environment may be quite significant. However, the presence of $\mathrm{H}_{2} \mathrm{O}^{+}$in the positive ion mass spectra studies to D-ribose ${ }^{13,15}$ lends support to the possibility of a concerted mechanism where an $\mathrm{H}$ and $\mathrm{OH}$ are abstracted, resulting in a water molecule formation. Such can be regarded as a non-harmful agent to the surrounding molecular framework of the DNA/RNA.

In DEA studies to several (bio)molecular targets, the dominant fragmentation channels result from very low energy resonances (often as low as $\sim 0 \mathrm{eV}$ ) consisting of vibrational Feshbach resonances. ${ }^{32}$ This can be rationalized by the fact that, in DEA, accessing high-energy resonances (such as formation of $\mathrm{NCO}^{-}$in uracil/thymine ${ }^{38}$ ) will mostly result in autodetachment, rather than in fragmentation. However, in atom-molecule collisions, there are strong evidences that autodetachment is significantly suppressed, enhancing fragment formation. Such is the case for uracil and thymine and is also the case for D-ribose. As far as authors are aware, electron transfer studies to D-ribose are completely unprecedented, with the most similar technique with which to compare being DEA studies. DEA studies on D-ribose show that the main fragmentation channels consist of near $0 \mathrm{eV}$ shape resonances that result in abstraction of one or more $\mathrm{H}$ and $\mathrm{OH}$ radicals, thereby not causing break of the sugar ring. ${ }^{13}$ However, less intense fragmentation channels at higher electron energies $(5-10 \mathrm{eV})$ do result in ring-breaking. ${ }^{13}$ We notice that extended DEA studies will be of particular relevance in order to attempt a more thorough knowledge of the mechanisms behind the fragmentation pathways, in particular, unreported anionic fragments. This may eventually lead to the understanding of possible damage mechanisms that this entails to the 
DNA molecule as a whole. However, it is interesting to mention the analogy that can be made between electron transfer and the presence of electron-donating elements in the vicinity of the DNA molecule. While this is an admittedly gross approximation, we suggest that it can be viewed as means to study molecule(atom)-molecule interactions between radicals (e.g., $\mathrm{O}^{\bullet}$ and $\mathrm{OH}^{\bullet}$ are formed from the water radiolysis) and the various components of the DNA macromolecule. Interestingly, higher-energy shape resonances in D-ribose have been identified, ${ }^{11}$ but are, owing to their low lifetimes, generally ignored as not being very important in the context of low-energy electron damage to DNA. Though, the present results highlight that this may not be the case. We have shown that the presence of a third body near the temporary negative ion (TNI) can greatly affect its fragmentation pathways and as such, formation of TNIs through the aforementioned resonances cannot, and should not, be disregarded.

However, it is known that the sugar unit in DNA has a furanosic form. As such, studies with furanosic sugars, namely, THF (which is an ether but is a known sugar surrogate), need to be performed in order to ascertain how important this characteristic is in the discussion of DNA/RNA sugar substitutes. Indeed, it has been shown that, for both THF and furan, no low-energy resonances $(<5 \mathrm{eV})$ appear. ${ }^{15}$ This is in contrast to deoxyribose, D-ribose, and fructose.

\section{ACKNOWLEDGMENTS}

D.A. and F.F.S. acknowledge the Portuguese Foundation for Science and Technology (FCT-MEC) for a post-graduate Grant No. SFRH/BD/61645/2009 and postdoctoral Grant No. SFRH/BPD/68979/2010, respectively. We are also grateful to the partial funding from the Portuguese research Grant Nos. PEst-OE/FIS/UI0068/2011 and PTDC/FIS-ATO/1832/2012 through FCT-MEC. P.L.-V. acknowledges his visiting professor position at The Open University, UK. The Spanish Ministerio de Economía y Competitividad (Project No. FIS 2012-31230) is also acknowledged. Some of this work forms part of the EU/ESF COST Actions Nano-IBCT-MP1002 and The Chemical Cosmos-CM0805.

${ }^{1}$ B. Boudaïffa, P. Cloutier, D. Hunting, M. A. Huels, and L. Sanche, Science 287, 1658 (2000).

${ }^{2}$ F. Martin, P. Burrow, Z. Cai, P. Cloutier, D. Hunting, and L. Sanche, Phys. Rev. Lett. 93, 068101 (2004).

${ }^{3}$ A. G. Sanz, M. C. Fuss, A. Munoz, F. Blanco, P. Limão-Vieira, M. J. Brunger, S. J. Buckman, and G. Garcia, Int. J. Radiat. Biol. 88, 71 (2012).

${ }^{4}$ M. C. Fuss, A. Muñoz, J. C. Oller, F. Blanco, A. Williart, P. Limão-Vieira, M. J. G. Borge, O. Tengblad, C. Huerga, M. Téllez, and G. García, Appl. Radiat. Isot. 69, 1198 (2011).

${ }^{5}$ M. C. Fuss, A. Muñoz, J. C. Oller, F. Blanco, P. Limão-Vieira, A. Williart, C. Huerga, M. Téllez, and G. García, Eur. Phys. J. D 60, 203 (2010).

${ }^{6}$ J. C. Oller, A. Muñoz, J. M. Pérez, F. Blanco, P. Limão-Vieira, and G. García, Chem. Phys. Lett. 421, 439 (2006).
${ }^{7}$ M. C. Fuss, A. G. Sanz, A. Muñoz, T. P. D. Do, K. Nixon, M. J. Brunger, M.-J. Hubin-Franskin, J. C. Oller, F. Blanco, and G. García, Chem. Phys. Lett. 560, 22 (2013).

${ }^{8}$ M. C. Fuss, A. Muñoz, J. C. Oller, F. Blanco, M.-J. Hubin-Franskin, D. Almeida, P. Limão-Vieira, and G. García, Chem. Phys. Lett. 486, 110 (2010).

${ }^{9}$ M. Fuss, A. Muñoz, J. C. Oller, F. Blanco, D. Almeida, P. Limão-Vieira, T. P. D. Do, M. J. Brunger, and G. García, Phys. Rev. A 80, 052709 (2009).

${ }^{10}$ I. Bald, J. Kopyra, and E. Illenberger, Angew. Chem., Int. Ed. Engl. 45, 4851 (2006).

${ }^{11}$ I. Baccarelli, F. A. Gianturco, A. Grandi, N. Sanna, R. R. Lucchese, I. Bald, J. Kopyra, and E. Illenberger, J. Am. Chem. Soc. 129, 6269 (2007).

${ }^{12}$ C. Wang, J. Nguyen, and Q. Lu, J. Am. Chem. Soc. 131, 11320 (2009).

${ }^{13}$ S. Ptasińska, S. Denifl, P. Scheier, and T. D. Märk, J. Chem. Phys. 120, 8505 (2004).

${ }^{14}$ T. Sommerfeld, J. Chem. Phys. 126, 124301 (2007).

${ }^{15}$ P. Sulzer, S. Ptasinska, F. Zappa, B. Mielewska, A. R. Milosavljevic, P. Scheier, T. D. Märk, I. Bald, S. Gohlke, M. A. Huels, and E. Illenberger, J. Chem. Phys. 125, 044304 (2006).

${ }^{16}$ I. Bald, J. Kopyra, I. Dabkowska, E. Antonsson, and E. Illenberger, J. Chem. Phys. 126, 074308 (2007).

${ }^{17}$ L. Sanche, Nature (London) 461, 358 (2009).

${ }^{18}$ K. Miaskiewicz and R. Osman, J. Am. Chem. Soc. 116, 232 (1994).

${ }^{19}$ P. Limão-Vieira, A. M. C. Moutinho, and J. Los, J. Chem. Phys. 124, 054306 (2006).

${ }^{20}$ A. W. Kleyn and A. M. C. Moutinho, J. Phys. B 34, R1 (2001).

${ }^{21}$ F. Ferreira da Silva, M. Lança, D. Almeida, G. García, and P. Limão-Vieira, Eur. Phys. J. D 66, 78 (2012).

${ }^{22}$ F. Ferreira da Silva, D. Almeida, R. Antunes, G. Martins, Y. Nunes, S. Eden, G. Garcia, and P. Limão-Vieira, Phys. Chem. Chem. Phys. 13, 21621 (2011).

${ }^{23}$ D. Almeida, R. Antunes, G. Martins, S. Eden, F. Ferreira da Silva, Y. Nunes, G. Garcia, and P. Limão-Vieira, Phys. Chem. Chem. Phys. 13, 15657 (2011).

${ }^{24}$ D. Almeida, F. Ferreira da Silva, G. García, and P. Limão-Vieira, Phys. Rev. Lett. 110, 023201 (2013).

${ }^{25}$ F. Ferreira da Silva, C. Matias, D. Almeida, G. García, O. Ingólfsson, H. D. Flosadottir, S. Ptasińska, B. Puschnigg, P. Scheier, P. Limão-Vieira, and S. Denifl, "NCO" , a key fragment upon dissociative electron attachment and electron transfer to pyrimidine bases: site selectivity for a slow decay process," J. Am. Soc. Mass Spectrom. (to be published), (2013).

${ }^{26}$ R. Antunes, D. Almeida, G. Martins, N. J. Mason, G. Garcia, M. J. P. Maneira, Y. Nunes, and P. Limão-Vieira, Phys. Chem. Chem. Phys. 12, 12513 (2010).

${ }^{27}$ H. P. Fenzlaff and E. Illenberger, Int. J. Mass Spectrom. Ion Process. 59, 185 (1984).

${ }^{28}$ D. Almeida, R. Antunes, G. Martins, G. Garcia, R. W. McCullough, S. Eden, and P. Limão-Vieira, Int. J. Mass. Spectrom. 311, 7 (2012).

${ }^{29}$ L. P. Guler, Y. Yu, and H. Kentta, J. Phys. Chem. A 106, 6754 (2002).

${ }^{30}$ T. Sommerfeld, J. Phys. Chem. A 108, 9150 (2004).

${ }^{31}$ A. M. Scheer, K. Aflatooni, G. Gallup, and P. Burrow, Phys. Rev. Lett. 92, 068102 (2004).

${ }^{32}$ P. D. Burrow, G. A. Gallup, A. M. Scheer, S. Denifl, S. Ptasinska, T. Märk, and P. Scheier, J. Chem. Phys. 124, 124310 (2006).

${ }^{33}$ T. Sommerfeld, Phys. Chem. Chem. Phys. 4, 2511 (2002).

${ }^{34}$ A. W. Kleyn, J. Los, and E. A. Gislason, Phys. Rep. 90, 1 (1982).

${ }^{35}$ F. A. Gianturco, F. Sebastianelli, R. R. Lucchese, I. Baccarelli, and N. Sanna, J. Chem. Phys. 128, 174302 (2008).

${ }^{36}$ S. Ptasińska, S. Denifl, V. Grill, T. D. Märk, P. Scheier, S. Gohlke, M. A. Huels, and E. Illenberger, Angew. Chem., Int. Ed. Engl. 44, 1647 (2005).

${ }^{37}$ S. Ptasińska, S. Denifl, V. Grill, T. D. Märk, E. Illenberger, and P. Scheier, Phys. Rev. Lett. 95, 093201 (2005).

${ }^{38}$ S. Denifl, S. Ptasińska, G. Hanel, B. Gstir, M. Probst, P. Scheier, and T. D. Märk, J. Chem. Phys. 120, 6557 (2004). 